\title{
RANDOMIZED DOUBLE BLIND PLACEBO CONTROLLED TRIAL TO ASSESS THE EFFICACY AND TOLERABILITY OF LEVOSULPIRIDE IN DYSMOTILITY TYPE OF FUNCTIONAL DYSPEPSIA
}

\author{
Lima Koruthara Mohanan'1, Bharathan Cherussery Sankaran ${ }^{2}$
}

${ }^{1}$ Assistant Professor, Department of Pharmacology, Government Medical College, Thrissur.

2 Professor, Department of Pharmacology, Government Medical College, Thrissur.

ABSTRACT
BACKGROUND
Treatment of functional dyspepsia is often challenging due to involvement of multiple pathophysiological mechanisms and
heterogeneous group of symptoms for the patients. Though several prokinetic drugs have been tried, none of them have established
long-term efficacy and safety. Levosulpiride is a newer prokinetic drug with D2 blocking and 5HT4 agonistic action, which was
compared with placebo for assessing its efficacy and safety.

AIM

To study the efficacy of Levosulpiride in dysmotility type of functional dyspepsia.

\section{SETTING AND DESIGN}

Department of Gastroenterology, Government Medical College, Calicut. Department of Pharmacology, Government Medical College, Calicut. Randomized double blind placebo controlled trial.

\section{MATERIALS AND METHODS}

Patients were randomly assigned in two groups (30 patients each) to receive either Levosulpiride or Placebo. Patients assigned to the Levosulpiride group received the same $25 \mathrm{mg}$ three times daily and the Placebo group received identically looking table ts three times daily. Patient's baseline symptoms were recorded. Only patients with predominant bloating were considered. The symptoms were graded on a 4-point scale of the Global Symptom Score Scale. Intensity and frequency of symptoms were graded. Patients were reassessed at the end of every 2 weeks and 4 weeks. Assessment of the symptom relief was done at the end of 2 weeks and 4 weeks on a 5-point scale as Subjective Global Assessment of Relief scale.

\section{STATISTICAL ANALYSIS}

Statistical analysis was done using Paired and Independent Sample T test.

\section{RESULTS}

Compared to placebo, Levosulpiride produced highly significant $(\mathrm{p}<0.001)$ improvement in symptom score both at 2 weeks and 4 weeks. On comparing subjective global assessment score, Levosulpiride produced significant $(\mathrm{p}<0.05)$ improvement at 2 weeks and highly significant $(\mathrm{p}<0.001)$ improvement at 4 weeks.

\section{CONCLUSION}

Levosulpiride has better efficacy than placebo in relieving dysmotility symptoms in patients with functional dyspepsia and it is well tolerated by patients.

\section{KEYWORDS}

Functional Dyspepsia, Prokinetic Drugs, Levosulpiride.

HOW TO CITE THIS ARTICLE: Mohanan LK, Sankaran BC. Randomized double blind placebo controlled trial to assess the efficacy and tolerability of levosulpiride in dysmotility type of functional dyspepsia. J. Evolution Med. Dent. Sci. 2016;5(30):1506-1510, DOI: $10.14260 /$ jemds/2016/355

\section{INTRODUCTION}

Dyspepsia is a common medical problem characterized by heterogeneous group of upper abdominal symptoms. Among the dyspepsia patients, $60 \%$ do not have a significant focal or structural lesion identified at upper endoscopy.

Financial or Other, Competing Interest: None.

Submission 24-02-2016, Peer Review 18-03-2016,

Acceptance 25-03-2016, Published 12-04-2016.

Corresponding Author:

Dr. Lima Koruthara Mohanan,

Orukkuthil House, Iringole $P O$,

Pattal, Perumbavoor

Ernakulam-683545.

E-mail: lima.nevin@gmail.com

DOI: $10.14260 /$ jemds/2016/355
These patients are known as having functional dyspepsia or non-ulcer dyspepsia. ${ }^{1}$ According to the most recent 2006 Rome III criteria, functional dyspepsia must include one or more of following symptoms: bothersome postprandial fullness, early satiation, epigastric pain, epigastric burning with no evidence of structural disease including at upper endoscopy, which is likely to explain the symptoms. Criteria should be fulfilled for at least 3 months with symptom onset at least 6 months previously. ${ }^{2}$ Symptoms are usually categorized as ulcer like (Burning sensation), dysmotility like (Nausea, bloating, early satiety, anorexia) or unspecified. ${ }^{3}$

The pathophysiology of functional dyspepsia is not well understood. Some of the reasons implicated in the pathophysiology of functional dyspepsia include motility disorders, non-motility disorders and psychosocial factors. ${ }^{4}$ 
Disorders of gastric motor function are seen in $60 \%$ of patients with functional dyspepsia. The motility disorder will lead to delayed gastric emptying, impaired gastric accommodation and myoelectric abnormalities. Non-motility disorders include visceral hypersensitivity and Helicobacter pylori infection.

Psychological disorders such as anxiety and depression are found in higher proportion in patients with functional dyspepsia. Psychosocial factors determine how a person perceives, interprets and responds to the altered gastrointestinal physiology. Thus the symptoms of functional dyspepsia arise due to a complex interaction between altered gastrointestinal physiology and psychosocial factors. Other possible pathophysiologic mechanism for non-ulcer dyspepsia include bile reflux into the stomach, viral induced gastritis, malabsorption of carbohydrate, parasitic infection.

Treatment of functional dyspepsia depends on the predominant symptom. Patients with predominant nausea and bloating may have motility dysfunction and may benefit from treatment with a prokinetic agent. Patients with pain as the predominant symptom may have mucosal disease or Helicobacter pylori infection. Antisecretory drugs produce a modest benefit in patients with functional dyspepsia. Efficacy of antidepressants in the management of functional dyspepsia is questionable. Anti-Helicobacter Pylori treatment produces a small therapeutic gain in Helicobacter pylori positive patients with functional dyspepsia.

Prokinetic agents are often considered as the most effective medication for the management of functional dyspepsia. They decrease gastroesophageal reflux, improve gastric emptying and facilitate accommodation. ${ }^{5}$ Most of the currently available Prokinetic drugs like Metoclopramide, Domperidone and Mosapride have been tried in functional dyspepsia. But none of them have established long-term efficacy and safety. ${ }^{6-8}$ As it is a functional disease treatment often is challenging, because there is a need to balance medical management strategies with due importance to psychological factors of the patient.

Levosulpiride is a new prokinetic drug. Levosulpiride is the levorotatory enantiomer of sulpiride and it is a substituted benzamide, has very recently been launched in India. Between the two enantiomers, the levo enantiomer is the biologically active form, which is more potent than Sulpiride. ${ }^{9}$ It has dopamine $\mathrm{D}_{2}$ receptor blocking activity in the central nervous system and in the peripheral submucosal and myenteric plexus of gastrointestinal tract. It relaxes the pyloric sphincter and increases the duodenal and jejunal peristalsis leading to accelerated gastric emptying and intestinal transit. It also has moderate agonistic effects at serotonin $5-\mathrm{HT}_{4}$ receptor, a property that further contributes its prokinetic action. ${ }^{10}$

At low doses Levosulpiride blocks dopamine autoreceptors and facilitate dopaminergic neurotransmission. So it is effective in negative symptoms of schizophrenia and for depressive and somatoform disorders. At high doses, postsynaptic $D_{2}$ receptors are blocked. Therefore, it is also effective for positive symptoms of schizophrenia. Levosulpiride possess a favourable $D_{2} / D_{3}$ ratio in their dopamine receptor blockade than typical antipsychotics. So usual side effects of typical antipsychotic like extrapyramidal symptoms, anticholinergic effects, hypotension and sedation are less frequent with the use of Levosulpiride.
After oral administration, the bioavailability is approximately $30 \%$. The time to peak plasma concentration is 3 hours, while the plasma elimination half-life ranges from 6 to 19 hours. Metabolism does not occur and the drug is excreted unchanged in the urine. The lack of hepatic metabolism makes metabolic interactions with other drugs very unlikely. ${ }^{11}$

According to tolerability studies, drowsiness or sedation is the most frequent adverse event with Levosulpiride. After prolonged administration side effects such as amenorrhea, gynaecomastia, galactorrhoea and alteration of libido may also occur in some patients. Levosulpiride is contraindicated in patients with pheochromocytoma, as it may cause hypertensive crisis. It is also contraindicated in patients with known hypersensitivity or intolerance to the drug, epilepsy, mania, pregnancy and lactation. 11

The usual daily dosage for adults is $25 \mathrm{mg}$ of Levosulpiride orally 3 times per day before meals. Levosulpiride is also effective in gastroesophageal reflux disease, irritable bowel syndrome, migraine, vertigo and postoperative or chemotherapy induced vomiting.

\section{MATERIALS AND METHODS}

This study compares the efficacy and tolerability of Levosulpiride against placebo in dysmotility type of functional dyspepsia. The study was designed as randomized double blind comparative clinical trial with duration of one year from November 2008 to November 2009. Patients were selected from the Outpatient Department of Gastroenterology, Government Medical College, Calicut and the study was approved by the Institutional Ethics Committee. Patients were randomly assigned in two groups to receive either Levosulpiride or Placebo.

The randomization was done using Latin square design. Complete history was elicited which covered personal data, duration of illness and other modalities of treatment. Laboratory tests including complete haemogram, liver function tests, renal function tests and blood glucose estimation were done. Endoscopic evaluation and ultrasonogram of the abdomen were done to rule out organic disease; 30 patients of both sexes in each group with symptoms of functional dyspepsia of dysmotility type and who fulfilled the below mentioned inclusion criteria were included in the study. All the patients had given written informed consent after proper explanation of the method of study.

\section{Inclusion Criteria}

- Patients above 18 years and below 60 years who satisfied Rome III criteria.

- Patients with predominant dysmotility symptoms of bloating.

\section{Exclusion Criteria}

- Below 18 years and above 60 years.

- Endoscopic evidence of ulcer disease.

- Severe oesophagitis.

- History of chronic intake of NSAIDs, anticoagulants.

- $\quad$ Epilepsy, mania.

- Pregnancy and lactation.

Patients assigned to the Levosulpiride group, received Levosulpiride $25 \mathrm{mg}$ three times daily, 30 minutes before major meals. Similarly, those in placebo group received 
identically looking tablets three times daily, 30 minutes before major meals. The patients were asked not to take any other medication related to their present condition.

Patient's baseline symptoms were recorded. The symptoms were graded on a 4-point scale (0-3) of the Global Symptom Score Scale (GSSS), which is a validated scoring system for functional dyspepsia. Intensity of symptoms were scored as $0=$ no symptoms, $1=$ mild symptoms, $2=$ moderate symptoms, $3=$ severe symptoms, prior to treatment. Frequency of symptoms were graded as $0=a b s e n t, 1=\geq 1-2$ days/week, $2=\geq 3-4$ days/week, $3=\geq 5$ days/week prior to treatment. The parameters considered were pain or discomfort, fullness, bloating, early satiety, nausea and burning. Only patients with predominant bloating were considered. Each parameter based on symptom was scored for intensity and frequency and total scores added up for Global Symptom Score. Patients receiving Levosulpiride or Placebo for the study were reassessed at the end of every 2 weeks and 4 weeks.

Assessment of the symptom relief was done at the end of 2 weeks and 4 weeks on a 5-point scale (1-5)- The patient's Subjective Global Assessment of Relief scale and scored as $1=$ marked or complete relief of symptoms, $2=$ moderate relief of symptoms, $3=$ slight relief of symptoms, $4=$ no relief of symptoms and $5=$ worsening of symptoms. The patients were instructed to report any adverse drug reaction that might be happening due to either Levosulpiride or Placebo.

\section{ANALYSIS OF DATA}

Statistical analysis was done using Statistical Package for Social Service (SPSS) version 16 software. Paired and Independent sample ' $t$ ' test were done for the analysis of data. Results were tabulated and significance was expressed according to the $\mathrm{p}$ value $<0.05$ (Significant) and $<0.001$ (Highly significant).

\section{RESULTS}

A total of 60 patients with dysmotility type of functional dyspepsia who fulfilled inclusion criteria were selected from the Department of Gastroenterology, Government Medical College, Calicut. They were randomly assigned into two groups to receive either Levosulpiride or Placebo. Data was collected and analysed. The comparison of baseline parameters is shown in Table 1. The comparison of Global Symptom Scores of Levosulpiride and Placebo group before treatment showed that there was no significant difference in symptom score (Table 2). Table 3 shows the global symptom score difference at 0 weeks and 2 weeks. As there is greater mean score in the Levosulpiride group ( $\mathrm{p}$ value $<.001$ ) shows that there is highly significant reduction of global score at 2 weeks in the Levosulpiride group.

Table 4 compares the global score difference at 0 weeks and 4 weeks. Here also greater mean score in the Levosulpiride group ( $p$ value $<.001$ ) shows that there is highly significant reduction of global score at 4 weeks in the Levosulpiride group. The comparison of mean total symptom score of both groups are shown in Figure 1. Table 5 compares the Subjective Global Assessment score of both groups. At 2 weeks, as per patient's assessment there is a significant reduction in symptoms in Levosulpiride group ( $p$ value $<0.05$ ). At 4 weeks, there is a highly significant reduction in symptoms in Levosulpiride group ( $p$ value $<0.001$ ).
Assessment of individual efficacy of Levosulpiride and Placebo are shown in Table 6-7 and Figure 2-3. The mean symptom score of Levosulpiride group changed from $20.57 \pm 4.0 \mathrm{SD}$ to $9.13 \pm 5.56 \mathrm{SD}$ and in the Placebo group changed from $20.33 \pm 5.65$ SD to $14.10 \pm 5.73$ SD after four weeks of treatment. Although symptom score significantly improved in both groups, analysis between two groups revealed that Levosulpiride was superior to Placebo in dysmotility type of functional dyspepsia. Only two patients in the Levosulpiride group reported mild somnolence, whereas the Placebo group did not report any adverse effect.

\begin{tabular}{|c|c|c|}
\hline Parameter & Levosulpiride & Placebo \\
\hline Mean age (Years) & $40.03 \pm 10.85 \mathrm{SD}$ & $38.43 \pm 11.64 \mathrm{SD}$ \\
\hline Sex (M:F) & $1: 2$ & $1: 1.14$ \\
\hline $\begin{array}{c}\text { Mean duration of } \\
\text { illness (Years) }\end{array}$ & $2.09 \pm 1.75 \mathrm{SD}$ & $2.48 \pm 2.16 \mathrm{SD}$ \\
\hline \multicolumn{2}{|c|}{ Table 1: Comparison of Baseline Parameters } \\
\hline
\end{tabular}

SD- Standard Deviation

\begin{tabular}{|c|c|c|c|}
\hline Group & Mean & t value & $\begin{array}{c}\mathbf{p} \\
\text { value }\end{array}$ \\
\hline $\begin{array}{c}\text { Levosulpiride }(\mathrm{n}=30) \\
\text { Placebo }(\mathrm{n}=30)\end{array}$ & $\begin{array}{l}20.57 \pm 4.07 \mathrm{SD} \\
20.33 \pm 5.65 \mathrm{SD}\end{array}$ & 0.18 & 0.855 \\
\hline \multicolumn{2}{|c|}{ Table 2: Global Symptom Score } \\
Analysis before Treatment
\end{tabular}

Independent sample t test

\begin{tabular}{|c|c|c|c|}
\hline Group & Mean & t value & p value \\
\hline $\begin{array}{c}\text { Levosulpiride }(\mathrm{n}=30) \\
\text { Placebo }(\mathrm{n}=30)\end{array}$ & $\begin{array}{c}7.47 \pm 4.27 \mathrm{SD} \\
3.80 \pm 3.30 \mathrm{SD}\end{array}$ & 3.72 & 0.000 \\
\hline \multicolumn{3}{|c|}{ Table 3: Global Symptom Score Analysis after } \\
Treatment (2 weeks) \\
\hline
\end{tabular}

Independent sample t test

\begin{tabular}{|c|c|c|c|}
\hline Group & Mean & t value & p value \\
\hline $\begin{array}{c}\text { Levosulpiride }(\mathrm{n}=30) \\
\text { Placebo }(\mathrm{n}=30)\end{array}$ & $\begin{array}{c}11.43 \pm 5.39 \mathrm{SD} \\
6.23 \pm 4.25 \mathrm{SD}\end{array}$ & 4.15 & 0.000 \\
\hline \multicolumn{3}{|c|}{ Table 4: Global Symptom Score Analysis after } \\
Treatment (4 weeks) \\
\hline
\end{tabular}

Independent sample $t$ test

\begin{tabular}{|l|l|l|c|}
\hline Group & Mean & t value & p value \\
\hline $\begin{array}{l}\text { SGA - 2 weeks } \\
\text { Levosulpiride ( } \mathrm{n}=30) \\
\text { Placebo }(\mathrm{n}=30)\end{array}$ & $\begin{array}{l}2.33 \pm .61 \mathrm{SD} \\
2.87 \pm .78 \mathrm{SD}\end{array}$ & -2.97 & 0.004 \\
\hline $\begin{array}{l}\text { SGA - 4 weeks } \\
\text { Levosulpiride ( }=30) \\
\text { Placebo (n=30) }\end{array}$ & $\begin{array}{l}2.03 \pm .41 \mathrm{SD} \\
2.57 \pm .63 \mathrm{SD}\end{array}$ & -3.87 & 0.000 \\
\hline \multicolumn{3}{|c|}{ Table 5: Subjective Global Assessment } \\
of Relief after Treatment \\
\hline
\end{tabular}

Independent sample t test

\begin{tabular}{|c|c|c|c|}
\hline & Mean & $\begin{array}{c}\mathbf{t} \\
\text { value }\end{array}$ & $\begin{array}{c}\mathbf{p} \\
\text { value }\end{array}$ \\
\hline $\begin{array}{c}\text { Symptom score before } \\
\text { treatment }\end{array}$ & $\begin{array}{c}20.57 \pm 4.07 \mathrm{SD} \\
9.13 \pm 5.56 \mathrm{SD}\end{array}$ & 11.63 & 0.000 \\
$\begin{array}{c}\text { Symptom score after } \\
\text { treatment }\end{array}$ & & \\
\hline SGA at 2 weeks & $\begin{array}{c}2.33 \pm 0.61 \mathrm{SD} \\
2.03 \pm 0.41 \mathrm{SD}\end{array}$ & 3.07 & 0.005 \\
\hline SGA at 4 weeks & Table 6: Levosulpiride (n=30) \\
\hline
\end{tabular}

Paired t test 


\begin{tabular}{|c|c|c|c|}
\hline & Mean & $\begin{array}{c}\mathbf{t} \\
\text { value }\end{array}$ & $\begin{array}{c}\mathbf{p} \\
\text { value }\end{array}$ \\
\hline $\begin{array}{l}\text { Symptom score before } \\
\text { treatment } \\
\text { Symptom score after } \\
\text { treatment }\end{array}$ & $\begin{array}{l}20.33 \pm 5.65 \mathrm{SD} \\
14.10 \pm 5.73 \mathrm{SD}\end{array}$ & 8.04 & 0.000 \\
\hline $\begin{array}{l}\text { SGA score at } 2 \text { weeks } \\
\text { SGA score at } 4 \text { weeks }\end{array}$ & $\begin{array}{l}2.87 \pm 0.78 \mathrm{SD} \\
2.57 \pm 0.63 \mathrm{SD} \\
\end{array}$ & 3.07 & 0.005 \\
\hline \multicolumn{4}{|c|}{ Table 7: Placebo $(n=30)$} \\
\hline
\end{tabular}

Paired t test

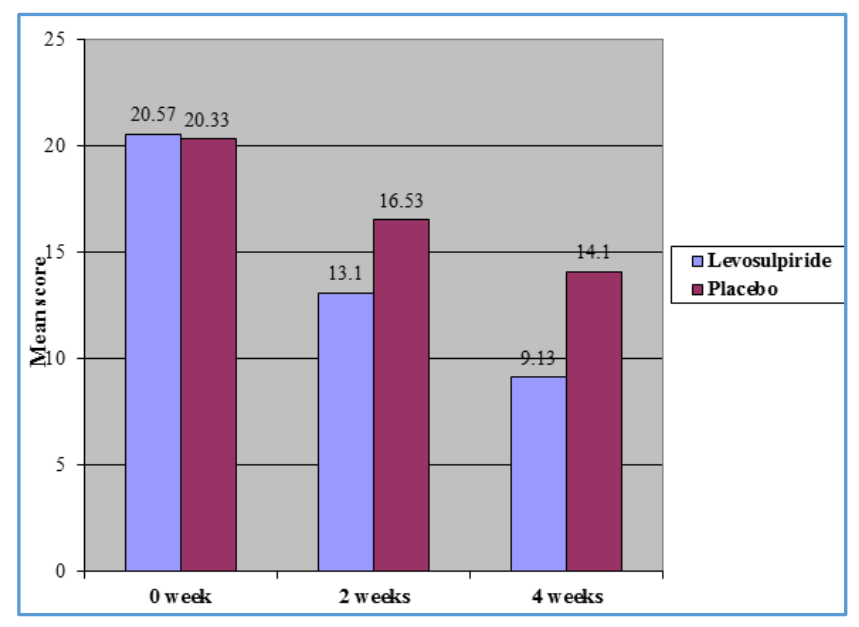

Fig. 1: Comparison of mean total symptom score in Levosulpiride and Placebo group

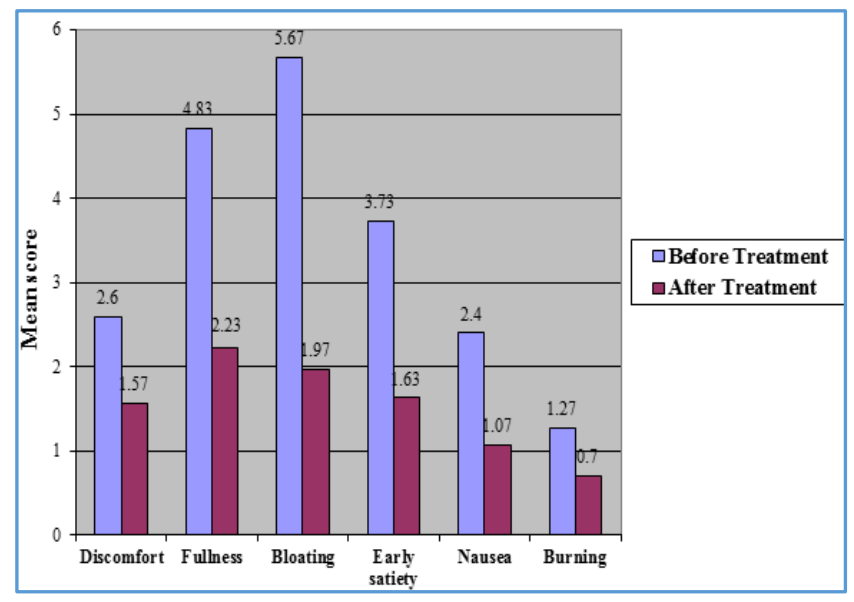

Fig. 2: Symptom score in Levosulpiride group

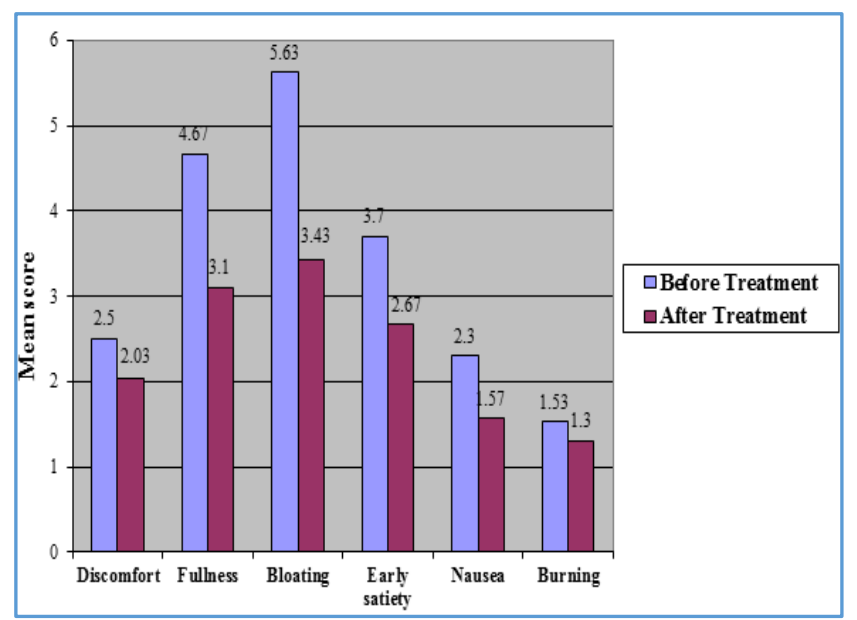

Fig. 3: Symptom score in Placebo group

\section{DISCUSSION}

Functional dyspepsia is a heterogeneous symptom complex which consists of nausea, vomiting, early satiety, postprandial fullness and epigastric pain without organic disease. The pathogenesis of dyspeptic symptoms is poorly understood and often related to motility disorders of the upper gastrointestinal tract.

There are several treatment options for functional dyspepsia which include antisecretory agents, prokinetic agents, Helicobacter pylori eradication, antidepressants and psychological interventions. Patients with predominant symptoms of nausea and bloating may have motility dysfunction and may benefit from treatment with a prokinetic agent. Most of the currently available prokinetic drugs like Metoclopramide, Domperidone, Mosapride and Itopride have either limited efficacy or safety.

Levosulpiride is the levo enantiomer of Sulpiride, which is an antipsychotic drug. This drug is having $5-\mathrm{HT}_{4}$ agonistic action with additional $\mathrm{D}_{2}$ receptor blocking activity contributes to the prokinetic action. Its efficacy in functional dyspepsia has been proved by a number of studies. This drug has been extensively compared with placebo and other conventional prokinetic drugs.

According to study by G. R. Corazza et al. Levosulpiride to be more efficacious than Metoclopramide, Domperidone and placebo in the short-term management of patients with functional dyspepsia, without relevant occurrence of side effects. ${ }^{10} \mathrm{~A}$ randomised controlled trial by Mangiameli A et al. showed that both Levosulpiride and Domperidone have positive influence on dyspeptic symptoms. But gastric emptying parameters were improved more effectively by Levosulpiride. 12

The present study is a randomized double blind placebo controlled trial to assess the efficacy and tolerability of Levosulpiride in dysmotility type of functional dyspepsia. Compared to Placebo, Levosulpiride produced highly significant $(\mathrm{p}<0.001)$ improvement in symptom score both at 2 weeks and 4 weeks. On comparing subjective global assessment score, Levosulpiride produced significant $(\mathrm{p}<0.05)$ improvement at 2 weeks and highly significant $(\mathrm{p}<0.001)$ improvement at 4 weeks. According to tolerability profile, only two patients in the Levosulpiride group reported mild somnolence.

The present study results are comparable to the study by Song CW et al. where Levosulpiride has been found to be more effective than placebo in dysmotility type of functional dyspepsia without any serious adverse effect and the study by $\mathrm{R}$ Lozano et al. which has found Levosulpiride is an effective and safe drug in the treatment of dysmotility like functional dyspepsia. ${ }^{13,14}$

In this study, we found another finding that statistically significant improvement in symptom score occurred in Placebo group also. This result was supported by Fermin Mearin et al. study, which has found that symptomatic response to Placebo is substantial in functional dyspepsia and clinical improvement might occur independently of detectable changes in the gastroduodenal motor activity or gastric hypersensitivity. ${ }^{15}$ Another placebo controlled trial of the prokinetic drug, Itopride by Gerald Holtmann et al. showed similar result like symptom score significantly improved in both groups. But the overall analysis revealed drug was superior to Placebo. ${ }^{16}$ 
In our study after overall assessment, it was demonstrated that Levosulpiride is more effective than placebo in treating dysmotility type of functional dyspepsia and it is well tolerated in patients with functional dyspepsia.

\section{CONCLUSION}

Functional dyspepsia refers to persistent or recurrent dyspepsia and has been found to have no obvious cause for the symptoms. Though there are several treatment options, prokinetic agents are found to be most effective agents in this condition.

Levosulpiride is a newer prokinetic drug with $\mathrm{D}_{2}$ receptor blocking and $5-\mathrm{HT}_{4}$ agonistic action. This drug has shown to be effective in the treatment of functional dyspepsia by many studies.

The present study, a randomized controlled double blind clinical trial was done to assess the efficacy and tolerability of Levosulpiride against placebo in dysmotility type of functional dyspepsia. This study has shown that Levosulpiride has better efficacy than placebo in relieving dysmotility symptoms in patients with functional dyspepsia. There were no serious adverse effects have been reported by either Levosulpiride or Placebo.

In this study only a small number of patients were included, i.e. 30 patients in each group and conducted within a limited period of time of one year. Further multicentric studies with large number of patients require to be carried out to establish the above data.

\section{REFERENCES}

1. Tack J, Bisschops R, Sarnelli G. Pathophysiology and treatment of functional dyspepsia. Gastroenterology 2004;127(4):1239-55.

2. Lin Chang. From rome to los angeles. The rome III criteria for the functional GI disorders (on line). Available at URL: http://www.medscape.com, view article/533460, Accessed Aug 21, 2006.

3. Talley NJ, Stanghellini V, Heading RC, et al. Functional gastroduodenal disorders. Gut 1999;45(II):II37-II42.

4. McQuaid K Dyspepsia. In: Feldman M, Friedman LS, Sleisenger MH. Sleisenger and Fordtran's gastrointestinal and liver disease: pathophysiology, diagnosis, management. Philadelphia, Pa: Saunders, 2002; 7th edn:102-103.
5. Lori M Dickerson, Pharm D, Dana E King. Evaluation and management of nonulcer dyspepsia. Am fam physician 2004;70(1):107-114.

6. Ganzini L, Casey DE, Hoffman WF, et al. The prevalence of metoclopromide induced tardive dyskinesia and acute extrapyramidal motor disorders. Arch of Int Med 1993;153(12):1469-75.

7. Keating JP, Rees M. Gynaecomastia after long term administration of domperidone. Post Grad Med J 1991;67(786):401-2.

8. Hallerbach BI, Bommelaer G, Bredberg E, et al. Dose finding study of mosapride in functional dyspepsia, a placebo controlled, randomized study. Aliment Pharmacol Ther 2002;16(5):959-67.

9. Mucci A, Nolfe G, Maj M. Levosulpiride: a review of its clinical use in psychiatry. Pharmacol res 1995;31(2):95101.

10. Corazza GR, Biagi F, Albano O, et al. Levosulpiride in functional dyspepsia. A multicentric double blind, controlled trial. Ital J Gastroenterol 1996;28(6):317-23.

11. Corazza GR, Tonini M. Levosulpiride for dyspepsia and emesis. A review of its pharmacology, efficacy and tolerability. Clinical Drug Invest 2000;19(2):151-162.

12. Mangiameli A, Brogna A, Catanzaro R, et al. Study with levosulpiride versus domperidone in the treatment of functional dyspepsia. Clin Ter 1994;144(2):107-14.

13. Song CW, Chun HJ, Kim CD, et al. Effect of levosulpiride in patients with functional dyspepsia accompanied by delayed gastric emptying. Korean J Intern Med 1998;13(1):15-21.

14. Lozano R, Concha MP, Montealegre A, et al. Effectiveness and safety of levosulpiride in the treatment of dysmotility like functional dyspepsia. Ther Clin Risk Manag 2007;3(1):149-155.

15. Fermin Mearin, Agustin Balboa, Natalia Zarate, et al. Placebo in functional dyspepsia: symptomatic, gastrointestinal motor and gastric sensorial response. The American Journal of Gastroenterlogy 1999;94:116-125.

16. Gerald Holtmann, Nicholas J Tally, Tobias Liebregts, et al. A placebo controlled trial of itopride in functional dyspepsia. New England J Med 2006;354:832-840. 